\title{
Using ANN to Estimate the Voltage of Unobservable Buses When One PMU or its Communication Fails
}

\author{
M. Gholami ${ }^{1}$, G. B. Gharehpetian ${ }^{1}$, B. Fahimi ${ }^{2}$ and M. J. Sanjari ${ }^{1}$ \\ 1 Electrical Engineering Department, Amirkabir University of Technology, Tehran. Iran \\ Phone/Fax number: +0098 2164543504,

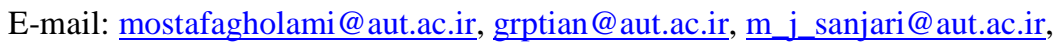 \\ 2 Electrical Engineering Department, University of Texas at Dallas \\ E-mail: fahimi@uta.edu
}

\begin{abstract}
In monitoring system, the PMUs send their data to a control center. If one PMU fails or its communication fail, the data of that PMU do not send to the control center. This lack of data leads to some unobservable buses. In this paper, Artificial Neural Network (ANN) has been used to estimate the voltage of unobservable buses. We implement this method in IEEE 14-Bus.
\end{abstract}

\section{Key words}

PMU, State Estimation, Artificial Neural Network (ANN), IEEE 14-Bus test system.

\section{Introduction}

Due to progress on Global Positioning System (GPS), the PMUs become available and can be used to get data from different points of a power system. This data is necessary for the supervisory control applications or on-line states assessment of a large scale power system. PMUs are able to take the online phasor measurements. This simultaneous measurement is achieved with voltage and current waveforms sampled by GPS signals. The ability of simultaneous measurement of PMUs, improve the monitoring, control and in turn the security level of power networks [1].

The Number of PMUs in a network is limited, because these devices are expensive and they cannot be installed on all buses. Due to placement of these devices a lot of papers have been published [2]. A lot of methods have been used to find the minimum number of needed PMUs and their places in a network [3], [4] and [5].

In this paper, we focus on situations that one PMU or its communication failed. In such a situation some parts of network become unobservable. This unobservability is dangerous, because maybe it causes to voltage collapse or other problems [6]. So, there must be one way to overcome this problem. One way is to use the traditional system on that area. But, the way that has been presented in this paper is to use the ANN to estimate the parameters of unobservable part of network.

\section{PMU Failure}

PMUs can get the magnitude and phase of voltage of the bus that is connected to, and the magnitude and phasor of current of lines that are connected to that bus and send them to a control center. So the PMUs need some communication tools which send their data to the control center. If one PMU fails or its communication have problem, the data of that PMU does not send to the control center. This lack of data leads to some unobservability in network.

In this paper, the ANN has been used to estimate the voltages of unobservable buses. The power network has been simulated by DIgSILENT software and the ANN has been carried out in MATLAB software.

The ANN should be trained by the results of the load flow analysis. The different scenarios have been randomly selected for different load or generation levels, which are generated by using Mont-Carlo method. In this method, a random number $(\mathrm{N})$ between 1 and $\mathrm{N}_{\mathrm{b}}$ (the number of buses) is generated. This number determines the number of buses, which should be changed. If a bus is a PQ or PV bus, in order to change its parameters, scenario 1 or 2 should be selected, respectively.

In the scenario 1, the load active power is randomly selected in the prespecified margin, as follows:

$$
P_{L, i}^{P Q} \in\left[P_{L, i}^{\min } \quad P_{L, i}^{\max }\right]
$$


In the scenario 2, one of the following three cases, is selected with equal probability, (i.e., 1/3):

Case 1: Only the load active power should be changed, as follows:

$$
P_{L, i}^{P V} \in\left[P_{L, i}^{\min } \quad P_{L, i}^{\max }\right]
$$

Case 2: Only the active power generation should be changed, as follows:

$$
P_{G, i}^{P V} \in\left[P_{G, i}^{\min } \quad P_{G, i}^{\max }\right]
$$

Case 3: Both, the load and the generation of the bus should be changed by using the following constraints:

$$
\begin{aligned}
& P_{L, i}^{P V} \in\left[\begin{array}{ll}
P_{L, i}^{\min } & P_{L, i}^{\max }
\end{array}\right] \\
& \text { and } \\
& P_{G, i}^{P V} \in\left[\begin{array}{ll}
P_{G, i}^{\min } & P_{G, i}^{\max }
\end{array}\right]
\end{aligned}
$$

The ANN used in this paper has 13 nodes on the input and one hidden layer with 20 nodes. The Levenberg-Marquart back-propagation algorithm has been used to identify ANN parameters.

In this step, 1000 different scenarios have been simulated by DIgSILENT. 900 of them have been selected to train the ANN, and 100 scenarios have been chosen to test the ANN. The error has been calculated for these 100 scenarios by the following equation:

$$
\operatorname{Error}(\%)=\frac{\text { Actual Value }- \text { Estimated Value }}{\text { Actual Value }} * 100
$$

The maximum and the average values of errors are calculated, to compare the different cases.

\section{The Proposed Algorithm}

The PMUs make the all part of network observable. It seems that PMUs are like lamps to light whole network.

If one PMU or its communication fails, some part of network becomes unobservable. It seems that some part of networks is dark.

To overcome this problem, the ANNs have been used. At first, scenarios have been produced. Then due to each PMU one ANN has been trained. The input of ANN that is related to a specific PMU is the voltage of observable buses by other PMUs, and the output of the ANN is the estimated voltage of unobservable bus or buses.

\section{Implementation on IEEE 14-Bus}

The proposed algorithm has been implemented on IEEE 14-Bus. It is shown in [7] that the IEEE 14-Bus system is observable by using 4 PMUs. These PMUs are installed on buses 2, 6, 7 and 9 .

To model the PMU failure, one of the PMUs should be omitted. Each PMU that omitted, some buses become unobservable. The buses which become unobservable are listed in Table-I.

Table-I: Unobservable buses due to lack of specific PMUs

\begin{tabular}{|c|c|}
\hline Omitted PMUs & Unobservable Buses \\
\hline 2 & $1,2,3,5$ \\
\hline 6 & $6,11,12,13$ \\
\hline 7 & 8 \\
\hline 9 & 10,14 \\
\hline
\end{tabular}

The errors of estimation due to each PMU fail, are listed below. The error of estimation when the PMU on bus 2 fails is listed in Table-II. The error of estimation related to PMU installed on bus 6 is listed in Table-III. The error of estimation of unobservable buses related to PMUs installed on buses 7 and 9, are listed in Table-IV and Table- $\mathrm{V}$, respectively.

Table-II: Error of voltage estimation of unobservable buses related to bus 2

\begin{tabular}{|c|c|c|}
\hline $\begin{array}{c}\text { Unobservable } \\
\text { Bus }\end{array}$ & $\begin{array}{c}\text { Maximum } \\
\text { Error \% }\end{array}$ & $\begin{array}{c}\text { Average } \\
\text { Error \% }\end{array}$ \\
\hline 1 & 0 & 0 \\
\hline 2 & 0 & 0 \\
\hline 3 & 2.44 & 0.44 \\
\hline 5 & 0.25 & 0.03 \\
\hline
\end{tabular}

Table-III: Error of voltage estimation of unobservable buses related to bus 6

\begin{tabular}{|c|c|c|}
\hline $\begin{array}{c}\text { Unobservable } \\
\text { Bus }\end{array}$ & $\begin{array}{c}\text { Maximum } \\
\text { Error \% }\end{array}$ & $\begin{array}{c}\text { Average } \\
\text { Error } \%\end{array}$ \\
\hline 6 & 0 & 0 \\
\hline 11 & 0.08 & 0.03 \\
\hline 12 & 0.27 & 0.09 \\
\hline 13 & 0.23 & 0.09 \\
\hline
\end{tabular}


Table-IV: Error of voltage estimation of unobservable buses related to bus 7

\begin{tabular}{|c|c|c|}
\hline $\begin{array}{c}\text { Unobservable } \\
\text { Bus }\end{array}$ & $\begin{array}{c}\text { Maximum } \\
\text { Error \% }\end{array}$ & $\begin{array}{c}\text { Average } \\
\text { Error \% }\end{array}$ \\
\hline 7 & 0.003 & 0.00008 \\
\hline
\end{tabular}

Table-V: Error of voltage estimation of unobservable buses related to bus 9

\begin{tabular}{|c|c|c|}
\hline $\begin{array}{c}\text { Unobservable } \\
\text { Bus }\end{array}$ & $\begin{array}{c}\text { Maximum } \\
\text { Error \% }\end{array}$ & $\begin{array}{c}\text { Average } \\
\text { Error \% }\end{array}$ \\
\hline 10 & 0.13 & 0.04 \\
\hline 14 & 0.41 & 0.16 \\
\hline
\end{tabular}

These tables show that the PMU which installed on bus 2 has more important than other PMUs. From this point of view, the system operators must have more accuracy about the PMU and its communication which is installed on bus 2 .

This method can be used to optimally placement of PMUs in a network. The objective function must be the less error of estimation of unknown parameters.

\section{Conclusion}

The PMUs bring some benefits to power system operators to keep a network stable and well managed. But these useful devices can face to a problem. Not only a PMU may be failed but also their communication links may be disconnected. In these cases, the state variables in some part of the network are not monitored to the power system operator that can leads to power system instability. In this paper a novel approach has been presented to conquer this problem. At first in off-line studies several ANN are trained to predict voltage magnitude if one PMU or its link fail. In contingency situations, these ANNs have been used by power system operators.

Due to the results, the most important PMUs have been found, and then the operators must make a decision about the specific PMU. For example the operator must put a reserve PMU on that bus.

In another hand this method can be used to allocation the PMU in a power system. The objective function is the minimum error of the voltage estimation due to PMU failure.

\section{Reference}

[1] B. Gou, "Generalized Integer Linear Programming Formulation for Optimal PMU Placement", IEEE Trans. on Power Systems, Vol. 23, No. 3, August 2008.

[2] D. J. Brueni and L. S. Heath, "The PMU Placement Problem," SIAM J.Discrete Math., vol. 19, no. 3, pp. 744-761, Dec. 2005.

[3] D. Dua, S. Dambhare, R. K. Gajbhiye, and S. A. Soman, "Optimal Multistage Scheduling of PMUPlacement: An ILP Approach" IEEE Trans.onPower Delivery, Vol. 23, No. 4, Oct. 2008

[4] N. H. Abbasy and H. M. Ismail, "A Unified Approach for the Optimal PMU Location for Power System State Estimation" IEEE Transon Power Systems, Vol. 24, No. 2, May 2009

[5] S. Chakrabarti and E. Kyriakides, "Optimal Placement of Phasor Measurement Units for Power System Observability" IEEE Trans. On Power Systems, Vol. 23, No. 3, August 2008.

[6] R. F. Nuqui and A. G. Phadke, "Phasor Measurement Unit Placement Techniques for Complete and Incomplete Observability" IEEE Trans.on Power Delivery, Vol. 20, No. 4, Oct. 2005

[7] A. G. Phadke, "Synchronisedphasor measurements in power systems," IEEE Comput. Applicat. Power, Vol. 6, No. 2, pp. 10-15, Apr. 1993. 